\section{CONSTRUINDO PONTES? O BRASIL DIANTE DA PRIMAVERA ÁRABE}

\author{
Guilherme Stolle Paixão e Casarões
}

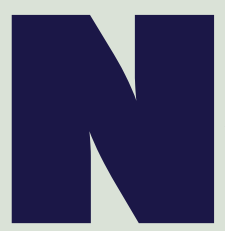

os primeiros anos deste novo século, a política externa brasileira (PEB) passou por um duplo movimento que nos permite, hoje, situar o país na condição de potência emergente ou potência intermediária. O primeiro deles, inaugurado pelo desejo do então presidente Luiz Inácio Lula da Silva e de seu chanceler Celso Amorim de instaurar uma política externa "ativa e altiva", foi responsável pelo expressivo aumento do perfil internacional do Brasil, seja em escopo ou profundidade de atuação. Observou-se, ademais, uma mudança de estratégia de inserção internacional: ao caráter prioritariamente comercial da PEB de outrora, fortemente associado à participação brasileira em foros multilaterais, foi somada uma dimensão política e bilateral de relevo, marcando a busca pela diversificação de parcerias e pelo retorno à cooperação sul-sul.

O Oriente Médio de uma maneira geral, e o mundo árabe em particular, parecem ter encontrado um lugar diferenciado nessa nova estratégia que caracterizou o governo Lula - e que ressoa, naturalmente, no início do mandato de sua sucessora, Dilma Rousseff. A ideia deste artigo, nesse sentido, é dupla: primeiro, pretende-se avaliar o papel do mundo árabe no contexto da inserção internacional recente da diplomacia brasileira, utilizando-se dos casos líbio e sírio. Argumenta-se que o ativismo comercial com a região não foi seguido por uma ampliação do status político do Brasil, o que inviabilizou, em termos gerais, a utilização desse eixo em particular como plataforma concreta da inserção nacional. O segundo propósito do texto é sugerir caminhos possíveis de atuação do Brasil com relação às recentes transformaçôes pelas quais passa a região - notadamente, a chamada Primavera Árabe - à luz de dois episódios: a crise civil líbia, que resultou na destituição de Muammar Khadafi, e a deterioração do regime sírio de Bashar al-Assad, que se arrasta por quase um ano e já deixou milhares de mortos. $\mathrm{O}$ argumento será estruturado na ordem exposta acima, e uma breve conclusão buscará dar conta dos resultados e contemplar as perspectivas futuras.

\footnotetext{
DOIS ATOS DA POLÍTICA EXTERNA BRASILEIRA PARA 0 MUNDO ÁRABE: LÍBIA E SÍRIA Os dois casos escolhidos para discussão - as relaçōes do Brasil com Líbia e Síria - ilustram com clareza os potenciais e as dificuldades que encontram nossa diplomacia ao estreitar os laços com o mundo árabe. Em primeiro lugar, estamos falando de dois países politicamente relevantes, isto é, naçōes com as quais aprofundar relaçōes acarreta impactos políticos mais amplos. A Líbia disputa primazia regional com outros "grandes" africanos, como a África do Sul, além de possuir relações delicadas com vizinhos como o Chade; a Síria, por sua vez, mantém rivalidades históricas (e sangrentas) com o Líbano e com Israel. Em segundo lugar, ambos os países possuem importância econômica, tendo no petróleo e
}

no potencial mercado consumidor seus pontos em comum. Quer dizer, são dois casos em que o Brasil pode avançar seus interesses comerciais. Por fim, trata-se de autocracias duradouras com uma conduta política reiteradamente condenada pela comunidade internacional - de vínculo com grupos terroristas a violaçôes constantes e massivas de direitos humanos. Relacionar-se com ambos, embora possa trazer dividendos tanto econômicos quanto políticos, acaba gerando uma série de arestas, que serão comentadas adiante.

As relaçōes entre o Brasil e o governo do coronel Muammar Khadafi - que chegara ao poder em 1969 - mantiveram-se em grande medida estáveis e focadas em sua dimensão comercial ao longo das últimas décadas. Seu auge correspondeu à busca brasileira por tornar-se um grande exportador de armamentos, em fins dos anos 1970, quando houve troca de visitas bilaterais, o estabelecimento de um Acordo Básico de Cooperação e participação de empresas nacionais em projetos na Líbia (1).

Com o isolamento internacional do governo de Khadafi ao longo da década seguinte, as relaçôes bilaterais limitaram-se a um nível "bastante discreto". Brasil e Líbia somente solidificaram suas relaçōes, entretanto, com a chegada do presidente Lula ao poder, em 2003. Dois fatos, ocorridos naquele mesmo ano, merecem menção. O primeiro deles foi a revogação completa, em território nacional, do regime de sançôes imposto ao regime de Khadafi - por meio do Decreto $\mathrm{n}^{\circ} 4.865$, de outubro. Mais importante, contudo, foi a visita do chefe de Estado brasileiro à Líbia, em dezembro. Tratou-se de um evento particularmente importante, pois elevou o nível do diálogo bilateral e consolidou a tendência ao estreitamento dos laços bilaterais (1).

Esse movimento, por outro lado, causou grande desconforto em alguns setores domésticos e repercutiu até mesmo na mídia internacional. Diante da visita de Lula aos líderes da região, na qual sobressaiu o encontro com Khadafi, o jornal britânico Financial Times salientou o caráter político da aproximação, entendida como uma provocação aos Estados Unidos. A revista Veja rotulou a diplomacia presidencial de "a turnê de Lula pelas ditaduras", chamando a política externa daquele governo de "insignificante, quando não grotesca" (2). Outro veículo influente, a Folha de S.Paulo, publicou editorial, à mesma época, condenando a "diplomacia de resultados" de Lula por "atropelar" direitos humanos, nas relaçóes com os autocratas do mundo árabe (3). Naquela oportunidade, o chanceler brasileiro, Celso Amorim, reiterou que a visita presidencial não seria ideológica, mas de negócios, buscando explorar oportunidades comerciais nas áreas de maquinário agrícola, aviação e construção civil (4).

Luiz Inácio Lula da Silva encontrou-se com o líder líbio mais três vezes até o fim de seu mandato. A primeira delas deu-se em ocasião da realização da primeira cúpula entre a América do Sul e a África, em novembro de 2006, na cidade nigeriana de Abuja. À época, afirmou que a Líbia estaria mudando, "caminhando para um processo de democratização" (5). Em julho de 2009, o presidente brasileiro, convidado a discursar na abertura da Cúpula da União Africana, regressou à nação líbia, reunindo-se com Khadafi em Sirte e chamando-o de "amigo e irmão". Poucos meses mais tarde, os líderes reencontraram-se na Venezuela, durante a II Cúpula América do Sul eÁfrica (6). Face às críticas ao pragmatismo dos relacionamentos 
externos brasileiros, o Itamaraty insistia em sua política de não intervenção nos assuntos internos de outros países e na necessidade de estreitar laços com nações do sul geopolítico.

Independentemente das conotações políticas das relações entre Brasil e Líbia, deve-se ressaltar a visível ampliação de seu comércio exterior. A Petrobras, em parceria com a estatal líbia National Oil Corporation (NOC), voltou a explorar óleo e gás na costa da nação árabe após 11 anos sem atividades, em meados de 2005 (7). De uma exportação média de US\$ 56 milhões entre 1989 e 2002, o Brasil passou a exportar nada menos que uma média anual de US\$ 232 milhões durante os anos Lula, atingindo o significativo valor de US\$ 456 milhōes em 2010. Com relação às importações, manteve-se uma média (com grandes oscilaçōes ano a ano) de US\$ 8,7 milhões entre 1989 e 2002, multiplicada para expressivos US\$ 468 milhōes, em média, durante o governo Lula. Somente no ano de 2008, importou-se da Líbia o equivalente a US\$ 1,4 bilhão, legando um vultoso déficit à balança comercial e contrariando uma tendência histórica de superávits do lado brasileiro (8).

A despeito da ampliação dos laços econômicos, não se pode dizer que os benefícios políticos extraídos da relação com a Líbia vieram na mesma proporção. Se, por um lado, conseguiu-se potencializar os fluxos comerciais, com impactos positivos sobre os interesses empresariais brasileiros, a necessária aproximação política - por vezes entendida até mesmo como identificação - colocou à prova a posição (historicamente confortável) da diplomacia brasileira. Pressões domésticas e de parte da comunidade internacional instaram o Itamaraty, nos últimos anos, a fazer defesas mais ostensivas da democracia no globo, de forma a justificar ou amenizar o estabelecimento de parcerias com autocratas como o líder líbio - obrigando, por exemplo, o presidente Lula a falar, de maneira constrangedora, de uma suposta "democratização" do regime de Khadafi. Ademais, ao lado das relaçôes com Cuba e com o Irã, a amizade entre Brasil e Líbia colocou em xeque a posição oficial brasileira no campo de direitos humanos.

No caso sírio, não foi diferente. Repete-se, com alguma frequência, que os laços bilaterais existentes entre Brasil e Síria são particularmente fortes devido à grande e influente comunidade árabe-brasileira, em sua maioria sírio-libanesa, que hoje ultrapassa os dez milhões de habitantes (9). De fato, as relações diplomáticas entre os dois países foram estabelecidas tão logo a Síria foi reconhecida como nação independente, ao fim da Segunda Grande Guerra, e mantiveram-se estáveis - embora mornas - desde então, sem alterações significativas a despeito das mudanças de regimes e governos em ambos os lados.

A reaproximação entre os países deu-se exatamente no governo Lula, que encontrou no regime sírio um importante ponto de apoio para as iniciativas da diplomacia brasileira, como a Cúpula América do Sul-Países Árabes (Aspa). Mais que isso, versa o argumento oficial que a Síria, em virtude de sua centralidade geopolítica no Oriente Médio, deveria gozar de mais espaço decisório nas questôes regionais candentes, como aquelas envolvendo a Palestina, o Líbano ou o Iraque (10).
Do ponto de vista político, a chancelaria brasileira buscou eximir-se de qualquer impedimento em seus contatos com a Síria. Alegou, para além da importância estratégica do regime de Bashar al-Assad em direção à paz na região, que a aproximação com os sírios almejava fomentar o diálogo bilateral entre estes e Israel, sobretudo no tocante à disputa pelas Colinas de Golã (10). Isso justificaria, entre outras coisas, as seis viagens oficiais realizadas por Celso Amorim a Damasco, bem como a visita do presidente Assad ao Brasil - sua primeira viagem transatlântica em uma década de governo - em julho de 2010. Naquela ocasião, o líder sírio reforçou o desejo de que o Brasil atuasse como "negociador ativo" no processo de paz entre árabes e israelenses. Israel, aliás, cujas relaçôes com o governo brasileiro vinham deteriorando-se desde o ano anterior, foi objeto de crítica de ambos os líderes em seus pronunciamentos (11).

No campo dos negócios, o estreitamento dos laços com a Síria buscou explorar um potencial comercial há muito latente, explicado pela significativa instabilidade regional. De fato, entre 1989 e 2002, o Brasil exportou, em média, US\$ 49 milhōes para o mercado sírio, correspondente a não mais que $0,1 \%$ do total de exportações brasileiras. Os números começaram a mudar no início do governo Lula, de modo que, durante seus dois mandatos, a média de exportações para a Síria atingiu a marca de US\$ 240 milhões, com o pico de US\$ 547 milhōes em 2010. Por outro lado, em decorrência da limitada pauta exportadora síria, o Brasil não importou mais que US\$ 4 milhōes, em média, no período até 2002. Daí em diante, o valor médio das importações daquele país chegou a US\$26 milhōes, donde se percebe uma balança claramente superavitária do lado brasileiro (10). Os dilemas são muito próximos da relação com a Líbia, com a diferença que, no caso sírio, o Brasil goza de um vínculo, digamos, "existencial" com os sírios, dificultando qualquer postura mais firme contra os abusos do regime de Assad.

\section{O BRASIL DIANTE DA PRIMAVERA ÁRABE: CONSTRUTOR DE PONTES?}

O quadro da política exterior brasileira passou por duas importantes inflexões no alvorecer de 2011. A primeira e mais importante delas foi a mudança de governo, com a eleição de Dilma Rousseff para suceder Lula, que havia governado o país por dois mandatos consecutivos. Muito embora a nova presidente, também do Partido dos Trabalhadores (PT), conferisse importantes traços de continuidade com relação à gestão anterior, a política externa abria-se como campo de inovação, sobretudo na temática dos direitos humanos. A presidente sinalizou reiteradas vezes, desde as eleiçôes, a centralidade da agenda de direitos humanos na sua gestão. A nomeação do embaixador Antonio Patriota para o MRE, mais discreto e menos polêmico que seu antecessor, viria a completar o quadro político em que, na interpretação de alguns (12), o Itamaraty reassumiria o comando das relaçōes exteriores, após oito anos competindo com uma forte diplomacia presidencial.

A postura brasileira com relação à violação de direitos humanos no Irã representou, nesse sentido, a concretização dessa inflexão de prioridades na agenda exterior. Pouco mais de três meses após a posse, 
o Brasil votou de maneira inédita no $\mathrm{CDH}$, alinhando-se aos Estados Unidos na designação de um relator especial para monitorar a situação humanitária no Irã. Foi, para muitos, o início da "era Dilma” em política externa (13). Restava, a partir dali, que a chancelaria estendesse sua posição na questão iraniana a circunstâncias semelhantes.

Nesse contexto, cumpre destacarmos a segunda inflexão ocorrida no início de 2011: a chamada Primavera Árabe. O termo, embora discutível em termos da analogia histórica que constrói, tem sido usado amplamente para descrever o conjunto de revoluções populares do mundo árabe iniciadas na Tunísia, em dezembro de 2010. Os efeitos da agitação social disseminaram-se rapidamente e foram amplificados com a destituição do presidente tunisiano, Zine El Abidine Ben Ali, no início de janeiro - após 23 anos no poder. Um mês mais tarde, diante de sucessivos dias de sangrentos confrontos entre manifestantes e exército na Praça Tahrir, no Cairo, foi a vez da renúncia do presidente egípcio, Hosni Mubarak, à frente do país desde 1981. Entre janeiro e fevereiro, revoltas populares abalaram virtualmente todas as naçōes árabes, com importantes efeitos - de mudanças institucionais a conflitos civis - em países como Argélia, Bahrein, Iêmen, Jordânia, Kuwait, Líbano, Líbia, Marrocos e Omã. Em meados de março, a fronteira final da estabilidade autoritária, a Síria, também é arrastada para uma duradoura sublevação civil.

Destes casos, foram particularmente caros à política externa brasileira os desdobramentos políticos na Líbia e na Síria. Em ambas as situações, o governo Dilma Rousseff foi deixado entre a cruz e a espada: apoiar os governos instituídos de Khadafi e Assad sinalizaria não somente uma posição cautelar com relação aos episódios, mas principalmente a disposição brasileira em manter os laços oficiais, o intercâmbio político e os fluxos comerciais com ambos os países. Por outro lado, a presidente deveria dar conta das cada vez mais patentes violações de direitos humanos perpetradas por aqueles regimes. A escolha seria mais simples, não fossem as promessas feitas pelo governo brasileiro em seus primeiros meses. As circunstâncias, contudo, impuseram uma necessidade de rápido ajustamento do Brasil às mudanças, face às quais a coerência da política externa deveria ser preservada - ao menos em discurso.

Tratava-se, de maneira particularmente visível, da dicotomia entre princípios e produtos postulada por Celso Amorim. O pragmatismo da política externa de Lula, por mais combatido que tivesse sido por alguns segmentos domésticos e internacionais, havia logrado resultados econômicos concretos, além de projetar, de maneira inequívoca, o Brasil no mundo. Durante seus oito anos de governo, temas como direitos humanos ou democracia, embora presentes, perderam ênfase. "Defendemos uma atitude de não indiferença, sem descuidar dos princípios basilares da soberania estatal e da não intervenção nas relações internacionais", atestou, em artigo, o chanceler de Lula.

Não parecia ser o caso da política externa de Dilma Rousseff. O novo governo deveria resguardar sua coerência não com relação aos princípios defendidos pela gestão anterior, mas àqueles evocados pela presidente como prioritários. Os direitos humanos deveriam, assim, balizar a ação brasileira diante da Primavera Árabe. No caso líbio, diante dos abusos massivos contra a população civil, espera- va-se que o Brasil referendasse as medidas tomadas pelo Conselho de Segurança das Nações Unidas, em remissão à doutrina internacional da "responsabilidade de proteger". No tocante à crise do regime de Bashar al-Assad, a expectativa era a de que o Brasil se juntasse ao coro das naçôes, muitas das quais árabes, que condenavam a violenta repressão do governo aos manifestantes e civis em geral.

Nenhuma das duas previsões concretizou-se de fato. Mesmo tendo votado a favor de sançôes econômicas contra Khadafi em fevereiro, a delegação brasileira absteve-se, em 17 de março, na autorização de uma zona de exclusão aérea em território líbio. A posição do Brasil esteve afinada com os votos dos demais Brics - China, Índia e Rússia - bem como da Alemanha. Em todos os casos, o argumento era semelhante: a chamada no-fly zone poderia abrir espaço para uma intervenção ocidental indesejada e desproporcional, liderada pela Otan. Neste caso, para além de uma questão de princípios - na qual colidem os imperativos humanitários e a soberania dos Estados havia uma importante dimensão comercial: o fortalecimento dos rebeldes líbios e a contínua instabilidade local poderiam colocar em risco o interesse corporativo de um número expressivo de empresas que passaram a atuar na Líbia durante o governo Lula (15).

Uma vez autorizada a intervenção militar na Líbia, o conflito civil estendeu-se por praticamente seis meses, contrapondo os rebeldes, amparados pela Otan, ao governo central de Khadafi. O longevo líder foi destituído em agosto e morto dois meses mais tarde pelas forças do Conselho Nacional de Transição (CNT), órgão rebelde que substituiu o antigo regime. Enquanto os Estados Unidos e grande parte das naçōes europeias já reconheciam o governo rebelde em julho, o governo brasileiro somente descredenciou os partidários de Khadafi de suas representaçôes oficiais em setembro. Criticado pela demora em aceitar o CNT, o ministro Antonio Patriota afirmou que o Brasil "reconhece Estados, e não governos" (16).

Ao contrário da questão líbia, que encontrou seu desfecho com a ajuda da comunidade internacional, a situação na Síria deteriora-se a cada dia e encontra-se paralisada no âmbito do Conselho de Segurança. Ao desejo das potências ocidentais de impor sançōes ao regime de Assad, contrapõem-se a vontade de Rússia e China, aliados tradicionais do governo sírio, que insistem na ampla negociação internacional e vetaram, em outubro de 2011, uma proposta de resolução respaldada pelos países europeus. O Brasil e seus parceiros emergentes, Índia e África do Sul, abstiveram-se novamente e causaram imediata reação da opinião pública. Em editorial, o jornal The New York Times chamou de "vergonhosa" a cumplicidade desses governos ao regime de Assad (17), podendo até mesmo comprometer aspirações futuras a uma cadeira permanente no CSNU.

Fora daquele âmbito, no entanto, o Itamaraty tem buscado desempenhar um papel relevante em relação à questão síria. Em declaração conjunta, Índia, Brasil e África do Sul, que compõem o Fórum Ibas, condenaram a violência prolongada na Síria mas reafirmaram seu compromisso com a soberania do país. A tentativa do grupo em mediar o conflito, ao passo que é capaz de elevar o perfil internacional seus membros, acabou gerando resultados ambíguos. De acordo com Lucia Nader e Fernando Sciré, da ONG Conectas de direitos humanos, "[a] estratégia brasileira pelo Ibas, com medo de ser condenatória, foi com- 
placente, abrindo precedentes para que governos violadores argumentem que estão cooperando" (18). Na Assembleia Geral das Naçōes Unidas e no $\mathrm{CDH}$, por outro lado, o Brasil votou contra o regime de Assad.

CONSIDERAÇÕES FINAIS Passado os primeiros anos do governo Dilma, algumas consideraçôes estão em ordem. Antes de tudo, deve-se ressaltar que a nova política externa brasileira, ainda que tenha passado por uma mudança de forma, mantém fortes traços de continuidade com a diplomacia de Lula no que diz respeito ao conteúdo. As promessas do início do governo foram escanteadas, seja diante da dificuldade em se manter a coerência nos foros internacionais, dada a secular tradição da chancelaria brasileira de não intervenção e respeito à soberania, seja em função dos compromissos previamente assumidos nos blocos "emergentes", Brics e Ibas.

Isso não significa que não haja espaço para a inovação ou para a mudança. A desvinculação dos votos brasileiros nos âmbitos do Conselho de Segurança e do Conselho de Direitos Humanos, por exemplo, mostra uma flexibilidade inédita da diplomacia nacional em condenar governos próximos por suas violaçôes de direitos humanos. Tomemos, por exemplo, o caso do Irã. O Brasil contrariou o regime dos aiatolás diversas vezes ao longo de 2011, levando até mesmo o porta-voz do presidente Ahmadinejad a dizer, em janeiro de 2012, que Dilma "destruiu anos de bom relacionamento" entre os dois países (19). Por mais sutil que tenha sido o impacto comercial do estremecimento das relações, é um indício de que a presidente está rumando o caminho inverso de seu antecessor - trocando produtos pelos princípios em que ela acredita.

No tortuoso caminho trilhado pela política externa brasileira nos movimentos populares do mundo árabe, contudo, o saldo ainda é negativo. Relatório recente da Human Rights Watch ressalta seu dissabor com a atuação da diplomacia dos emergentes, que parecia ser orientada "não pelas aspirações do povo árabe, mas mais por seu compromisso com visões ultrapassadas da soberania nacional, mesmo quando isso resulta na blindagem de regimes repressivos da necessidade urgente de pressão internacional" (20). Na mesma linha, críticos domésticos rotulam a atuação brasileira em favor dos direitos humanos na Síria de "tímida" (21). Os paradoxos observados na conduta da diplomacia do governo Dilma tornam essa postura errática ainda mais evidente.

O que fazer? Certamente, o caso líbio - que aparentemente chegou a um bom termo, com o reconhecimento internacional do CNT - não representa mais embaraços à PEB. Não obstante, ele trouxe consigo um conceito novo, o de "responsabilidade ao proteger", cunhado pela própria diplomacia brasileira quando da intervenção líbia. $\mathrm{O}$ argumento é simples: para além da aventada "responsabilidade de proteger" - corolário utilizado, no âmbito da ONU, para justificar ações humanitárias - a comunidade das nações deve prevenir, sempre que possível, qualquer tipo de ação armada, esgotar os meios pacíficos possíveis e monitorar o uso da força em campo.

A ideia pode ser útil na abordagem do conflito sírio, aproximando os interesses ocidentais das possibilidades diplomáticas de Rússia, China e dos demais emergentes. Nesse sentido, o fim do mandato brasileiro no Conselho de Segurança pode ser um ativo importante, ao reduzir as pressões pela coerência em busca de uma cadeira perma- nente naquele órgão. Agora cabe ao Brasil, valendo-se da tradicional criatividade de sua diplomacia, construir as pontes necessárias.

Guilherme Stolle Paixão e Casarões é professor de relaçôes internacionais das Faculdades Integradas Rio Branco e do Centro de Pesquisa e Documentação (CPDOC) da Fundação Getúlio Vargas. É pesquisador da Rede Interinstitucional de Pesquisa em Politica Externa e Regime Politico (Ripperp).

\section{NOTAS E REFERÊNCIAS BIBLIOGRÁFICAS}

1. Informações disponíveis no site do Ministério das Relações Exteriores (MRE): http://dai-mre.serpro.gov.br/atos-internacionais/ bilaterais/1978/b_48/ (acesso em setembro de 2012).

2. Alcântara, E. "A turnê de Lula pelas ditaduras". Veja, edição 1833, 17 de dezembro de 2003.

3. Gielow, I. "'Diplomacia de resultados' atropela direitos humanos". FoIha de S.Paulo, 04 de dezembro de 2003.

4. Na Líbia, Amorim diz que Brasil "não trocará princípios por produtos". Folha Online, 10 de dezembro de 2003.

5. Wasserman, R. "Lula defende encontro com Gaddafi na Nigéria". BBC Brasil, 30 de novembro de 2006.

6. Landim, R. "Kadafi: o 'amigo' de Lula". 22 de fevereiro de 2011. Disponível em http://blogs.estadao.com.br/sala-ao-lado/2011/02/22/ kadafi-o-amigo-de-lula/ (acesso em setembro de 2012).

7. Ripardo, S. "Petrobras fecha acordo de exploração com estatal líbia". Folha Online, 15 de março de 2005.

8. Dados do Ministério do Desenvolvimento, Indústria e Comércio. Disponíveis em http://www.mdic.gov.br/sitio/interna/interna. php?area $=5 \&$ menu $=576$.

9. Amorim, C. "Brazil and the Middle East: reflections on Lula's South-South cooperation". In: Cairo Review, Vol.2, p.50. 2011.

10. Idem, p.56.

11. Monteiro, T. “Com al-Assad, Lula rejeita que 'não há solução' para o Oriente Médio". O Estado de S. Paulo, 30 de junho de 2010.

12. Essa "nova característica" do governo Dilma veio para o bem, na opinião de Cantanhêde, E. "Atos, palavras, símbolos". Folha de S. Paulo, 12 de janeiro de 2011; mas não surtiu os devidos efeitos, conforme sugere Rossi, C. "Diplomacia de baixa voltagem". Folha de S. Paulo, 28 de agosto de 2011.

13. Corrêa, A. "Para estrangeiros, mudança de estilo é marca inicial da era Dilma". BBC Brasil, 8 de abril de 2011.

14. Amorim, C. "O Brasil e os direitos humanos: em busca de uma agenda positiva". In: Política Externa, Vol.18, no.2, p.75, 2009.

15. Elizondo, G. "Brazil's business in Libya". Al Jazeera Americas, 21 de fevereiro de 2011. Blogs.aljazeera.net.

16. Santos, D. "Brasil reconhece estados e não governos, diz Patriota sobre a Líbia". Portal G1, 23 de agosto de 2011.

17. "Isolating Assad". The New York Times, 31 de agosto de 2011.

18. Nader, L.; Sciré, F. "Mais quantas primaveras?". O Estado de S. Paulo, 04 de dezembro de 2011.

19. "Irã critica Dilma e diz que Lula faz muita falta". Folha de S.Paulo, 23 de janeiro de 2012.

20. Roth, K. "Time to abandon the autocrats and embrace rights". Human Rights Watch - World Report 2012. Disponível em http://www. hrw.org/world-report-2012/time-abandon-autocrats-and-embrace-rights (acesso em setembro de 2012).

21. Nader e Sciré, op. cit., 2011. 